Article

\title{
Persistency of Indigenous and Exotic Entomopathogenic Fungi Isolates under Ultraviolet B (UV-B) Irradiation to Enhance Field Application Efficacy and Obtain Sustainable Control of the Red Palm Weevil
}

\author{
Koko Dwi Sutanto ${ }^{1}$, Mureed Husain ${ }^{1, *}$, Khawaja Ghulam Rasool ${ }^{1}$, Akhmad Faisal Malik ${ }^{2}$, \\ Wahidah Hazza Al-Qahtani ${ }^{3}$ and Abdulrahman Saad Aldawood ${ }^{1}$ (D)
}

Citation: Sutanto, K.D.; Husain, M.; Rasool, K.G.; Malik, A.F.; Al-Qahtani, W.H.; Aldawood, A.S. Persistency of Indigenous and Exotic Entomopathogenic Fungi Isolates under Ultraviolet B (UV-B) Irradiation to Enhance Field Application Efficacy and Obtain Sustainable Control of the Red Palm Weevil. Insects 2022, 13, 103. https:// doi.org/10.3390/insects13010103

Academic Editor: Lara Maistrello

Received: 15 December 2021

Accepted: 7 January 2022

Published: 17 January 2022

Publisher's Note: MDPI stays neutral with regard to jurisdictional claims in published maps and institutional affiliations.

Copyright: (C) 2022 by the authors. Licensee MDPI, Basel, Switzerland. This article is an open access article distributed under the terms and conditions of the Creative Commons Attribution (CC BY) license (https:// creativecommons.org/licenses/by/ $4.0 /)$.
1 Department of Plant Protection, College of Food and Agriculture Sciences, King Saud University, P.O. Box 2460, Riyadh 11451, Saudi Arabia; ksutanto@ksu.edu.sa (K.D.S.); gkhawaja@ksu.edu.sa (K.G.R.); aldawood@ksu.edu.sa (A.S.A.)

2 Directorate of Estate Crops Protection, Ministry of Agriculture, Jakarta 12550, Indonesia; akhmadfaisal@pertanian.go.id

3 Department of Food Sciences and Nutrition, College of Food and Agriculture Sciences, King Saud University, P.O. Box 2460, Riyadh 11451, Saudi Arabia; wahida@ksu.edu.sa

* Correspondence: mbukhsh@ksu.edu.sa

Simple Summary: Entomopathogenic fungi have the potential to control insect pests However, field application has issues with germination and pathogenicity due to ultraviolet irradiation. The purpose of this study was to investigate the persistence of different local and exotic fungal isolates of Beauveria bassiana and Metarhizium anisopliae in the laboratory under various ultraviolet exposure times, to obtain a fungal isolate enabling long-term management of red palm weevil Rhynchophorus ferrugineus Olivier (Coleoptera: Dryophthoridae), a major pest of palm trees around the globe. After $300 \mathrm{~min}$ of ultraviolet radiation, the colony-forming unit of a certain fungal isolate has survived. The persistence of certain fungal isolates to ultraviolet irradiation has shown to be promising. Finding a persistent fungal isolate would be helpful in increasing fungal germination and increase its sustainability against harsh environmental conditions in the field. The overall aim of this research was to obtain sustainable control of the red palm weevil, which has become a major invasive pest in many areas outside its native range.

Abstract: The red palm weevil Rhynchophorus ferrugineus Olivier (Coleoptera: Dryophthoridae) has become a key invasive pest and major threat to the palm tree worldwide. Several entomopathogenic fungi are used in insect biological control programs. In the present study, persistency of different local and exotic fungal isolates of Beauveria bassiana and Metarhizium anisopliae was evaluated under UV-B irradiation with different exposure intervals. Several factors, including ultraviolet (UV) light, significantly decrease germination rate of fungi, as UV penetrates and damages their DNA. Several studies have investigated that UV-resistant conidia germinate better under harsh environmental conditions. Seven local and exotic fungi isolates ("BbSA-1", “BbSA-2", “BbSA-3", “MaSA-1", “BbIDN1", "MaIDN-1", and "MaIDN-2") were tested in the current study under UV-B irradiation having different UV exposure times (i.e., 15, 30, 60, 120, 180, 240, and $300 \mathrm{~min}$ ). The colony-forming unit (CFU) in each isolate was used to calculate the survival rate. Results indicated that survival rate of all the isolates decreased under UV-B irradiation for all exposure times compared to no exposure to UV-B irradiation. The CFU number decreased as the exposure time increased. Fungi isolates "MaSA-1", “BbSA-1", “BbSA-2", “MaIDN-1”, and "MaIDN-2” could persist after 300 min exposure to UV-B, while the remaining isolates, such as "BbIDN-1", and "BbSA-3", could not persist after $300 \mathrm{~min}$ exposure to UV-B. The ultimate objective of the present research was to explore an ultraviolet-tolerant fungal isolate that might be useful in the field application for the sustainable management of the red palm weevil, which has become a key invasive pest in many regions rather than its native range. Most of the fungus isolates studied in the present work were collected from Saudi Arabia's Al-Qatif region, where the red palm weevil has infested more than ten thousand trees, worth millions of riyals. 
Keywords: ultraviolet-B; CFU; Beauveria bassiana; Metarhizium anisopliae; germination

\section{Introduction}

The red palm weevil Rhynchophorus ferrugineus Olivier (Coleoptera: Dryophthoridae) is a crucial invasive pest and main danger to the palm species globally. It has damaged more than ten thousand of the date palm trees, worth millions of riyals, in Saudi Arabia's Al Qatif region [1]. Several entomopathogenic fungi are being utilized in insect biological control programs. Because entomopathogenic fungi are living organisms, they are severely harmed by the harsh environmental conditions in the field, and their efficacy is reduced as a result. The efficacy of microorganisms in the field is influenced by a number of factors, including ultraviolet (UV) irradiation. UV is well-known for its negative impact on the survival of some microbial control agents. Ultraviolet B (UV-B) has proved lethal for several microbial agents, particularly within 300 and $320 \mathrm{~nm}$ wavelengths [2]. UV irradiation primarily targets the DNA of the living organisms by reactive oxygen species (ROS), including deoxyribose oxidation and strand breakage, which creates a single oxygen atom $\left(\mathrm{O}_{2}\right)$ and peroxides $\left(\mathrm{H}_{2} \mathrm{O}_{2}\right)[3,4]$. The UV negatively affect DNA of several fungi, such as Beauveria bassiana Balls, (Hypocreales: Cordycipitaceae) [5], Verticillium lecanii Zare and Gams, (Hypocreales: Cordycipitaceae), and album Aphanocladium Preuss, (Hypocreales: Nectriaceae) [6]. Ultraviolet A (UV-A) delayed conidia germination of Metarhizium robertsii (Metchnikoff) Sorokin (Hypocreales: Clacivipitaceae) and Metarhizium acridum Driver and Milner, (Hypocreales: Clacivipitaceae) when grown on PDA medium [7]. The UV-B can reduce conidia viability by $>50 \%$ [8]. Similarly, the exposure of Metarhizium anisopliae (Metchnikoff) Sorokinn, (Hypocreales: Clacivipitaceae), and B. bassiana to ultraviolet C (UV-C) for $2 \mathrm{~h}$ reduced conidia viability by $85 \%$ after $24 \mathrm{~h}$ incubation [9]. Similarly, different Metarhizium isolates exhibited varying conidia germination when exposed to UV-B irradiation for varying times. Conidia germination started to decline $5 \mathrm{~h}$ after exposure and only $5 \%$ of the conidia germinated $8 \mathrm{~h}$ after exposure compared to control (no UV-B exposure), where germination ranged between 97 and 100\% [10].

Microorganisms are highly sensitive to extreme environments containing UV and high temperature [11]. Persistence of M. anisopliae (M.08/I05) has been tested under field conditions using an auto-contamination trap containing fungi isolates and $43-59.25 \%$ decrease in colony-forming unit (CFU) was recorded under $18-30{ }^{\circ} \mathrm{C}$ temperature and $60 \%$ relative humidity (RH) [12]. However, exposure of B. bassiana and M. anisopliae conidia to UV irradiation increased their viability [13]. Fungus isolates attained maximum pathogenicity against European corn borers Ostrinia nubilalis (Hübner) (Lepidoptera: Crambidae) following exposure to UV light (wavelength $254 \mathrm{~nm}$ for $45 \mathrm{~min}$ ), causing $100 \%$ larval mortality within 10 days [14]. Selective B. bassiana isolates resistant to UV irradiation have shown good performance that increased their effectiveness against the coffee borer beetle Hypothenemus hampei (Ferrari) (Coleoptera: Curculionidae) [15].

Different local and exotic fungi isolates of B. bassiana and M. anisopliae were tested for their persistence under different exposure times to UV-B in the laboratory. Finding a persistent fungal isolate would be helpful in increasing fungal germination and increase its sustainability against harsh environmental conditions in the field. The ultimate goal of this study was to find ultraviolet-tolerant fungal isolates that might be used in the field for the long-term management of the red palm weevil, which has become a major invasive pest in many areas outside of its natural habitat.

\section{Materials and Methods}

\subsection{Entomopathogenic Fungi Source}

Different indigenous isolates of B. bassiana and M. anisopliae (originally from Al-Qatif governorate and Riyadh region) were obtained either from the Ministry of Agriculture or collected by the first author from Saudi Arabia. The exotic isolates used in the study were 
collected from Kalimantan, Indonesia. All isolates were assigned a code based on their origin (SA for Saudi Arabia) and species (Bb for B. bassiana). The B. bassiana isolates were coded as "BbSA-1", "BbSA-2", and "BbSA-3". The M. anisopliae was coded as Ma and the isolate code was "MaSA-1". Similarly, Indonesian isolate (IDN) of B. bassiana was coded as "BbIDN-1", whereas those belonging to $M$. anisopliae were coded as "MaIDN-1" and "MaIDN-2". An identification key was used to identify the isolates based on morphological characteristics [16]. All these fungal isolates were previously pathogenicity tested against red palm weevil Rhynchophorus ferrugineus Olivier (Coleoptera: Dryophthoridae) stages in our laboratory [17]. Detailed information regarding the source of fungal isolates used in the study is given in Table 1. All isolates were cultured at the Economic Entomology Research Unit (EERU), Plant Protection Department, College of Food and Agriculture Sciences, King Saud University, Riyadh, Kingdom of Saudi Arabia (KSA).

Table 1. Background information on the entomopathogenic fungal isolates used in the present study.

\begin{tabular}{|c|c|c|c|c|c|}
\hline Fungi & Isolates' Code & $\begin{array}{l}\text { Insect Species/ } \\
\text { Order }\end{array}$ & $\begin{array}{l}\text { Source of } \\
\text { Isolation }\end{array}$ & $\begin{array}{l}\text { Original Location (s) } \\
\text { of Isolates }\end{array}$ & Coordinates \\
\hline B. bassiana & BbSA-1 & $\begin{array}{c}\text { Red palm weevil } \\
\text { R. ferrugineus/Coleoptera }\end{array}$ & adult & $\begin{array}{c}\text { Al Qatif, } \\
\text { Saudi Arabia }\end{array}$ & $\begin{array}{l}\mathrm{N}: 26.34437^{\circ} \\
\mathrm{E}: 43.69217^{\circ}\end{array}$ \\
\hline B. bassiana & BbSA-2 & $\begin{array}{c}\text { Cotton leafworm Spodoptera litura } \\
\text { /Lepidoptera }\end{array}$ & larva & $\begin{array}{l}\text { Al Qatif, } \\
\text { Saudi Arabia }\end{array}$ & $\begin{array}{l}\mathrm{N}: 24.41867^{\circ} \\
\mathrm{E}: 46.65408^{\circ}\end{array}$ \\
\hline B. bassiana & BbSA-3 & $\begin{array}{c}\text { Red palm weevil } \\
\text { R. ferrugineus/Coleoptera }\end{array}$ & adult & $\begin{array}{l}\text { Al Qatif, } \\
\text { Saudi Arabia }\end{array}$ & $\begin{array}{l}\mathrm{N}: 26.35231^{\circ} \\
\mathrm{E}: 43.71789^{\circ}\end{array}$ \\
\hline B. bassiana & BbIDN-1 & $\begin{array}{l}\text { Corn earworm Helicoverpa zea } \\
\text { /Lepidoptera }\end{array}$ & larva & Kalimantan, Indonesia & $\begin{array}{l}\mathrm{N}:-0.02633^{\circ} ; \\
\mathrm{E}: 109.3425^{\circ}\end{array}$ \\
\hline M. anisopliae & MaSA-1 & $\begin{array}{l}\text { Red palm weevil } \\
\text { R. ferrugineus } \\
\text { /Coleoptera }\end{array}$ & adult & Riyadh, Saudi Arabia & $\begin{array}{c}\mathrm{N}: 24.41867^{\circ} \\
\mathrm{E}: 46.65408^{\circ}\end{array}$ \\
\hline M. anisopliae & MaIDN-1 & $\begin{array}{l}\text { Coconut Rhinoceros beetle } \\
\text { Oryctes rhinoceros / Coleoptera }\end{array}$ & adult & Kalimantan, Indonesia & $\begin{array}{l}\mathrm{N}:-0.02633^{\circ} ; \\
\mathrm{E}: 109.3425^{\circ}\end{array}$ \\
\hline M. anisopliae & MaIDN-2 & $\begin{array}{l}\text { Coconut leaf beetle Brontispa } \\
\text { longissima/Coleoptera }\end{array}$ & adult & Kalimantan, Indonesia & $\begin{array}{l}\mathrm{N}:-0.03962^{\circ} \\
\mathrm{E}: \\
109.3128^{\circ}\end{array}$ \\
\hline
\end{tabular}

\subsection{Isolation and Culture of Fungal Isolates on Potato Dextrose Agar Medium}

The body surface of the red palm weevil adults (cadavers) infected with fungi was sterilized with 5\% sodium hypochlorite for $1 \mathrm{~min}$ and washed twice with sterile distilled water [18]. After washing, a small part of the cadaver was dried on filter paper before transferring to potato dextrose agar (PDA) (Scharlau, Microbiology 01-483, Barcelona, Spain) medium. Fungi were allowed to grow on PDA medium at $85 \pm 5 \%$ relative humidity and $25 \pm 2{ }^{\circ} \mathrm{C}$ temperature for 7 days [17]. A hyphen tip technique was used for the purification of fungi [19].

A total $30 \mathrm{~g}$ PDA powder was thoroughly mixed with 11 distilled water and autoclaved at $121^{\circ} \mathrm{C}$ for $20 \mathrm{~min}$ (sterilization). Autoclaved liquid medium was poured onto sterilized Petri dishes $(10 \mathrm{~cm}$ in diameter) as a thin layer. After solidification of the PDA, $1 \mathrm{~cm}$ of each culture isolate was taken with a sterile scalpel and transferred to the center of the PDA plate. The inoculated plates were incubated at $25 \pm 2{ }^{\circ} \mathrm{C}$ temperature and $85 \pm 5 \%$ relative humidity in an incubator (Orbital Incubator, Stuart, SI 500). Initially, the first purification of the isolates was grown on PDA medium, followed by screening of the isolates that germinated rapidly. The purification was performed 15 times through PDA medium to enhance the performance of the isolates [17]. Conidia were produced from an isolated fungus that was cultivated on PDA medium plates for 14 days, after which each plate was supplemented with $10 \mathrm{~mL}$ sterile distilled water mixed with Triton-X $(0.1 \%)$ and then harvested by scraping the inoculum [20]. The concentration of conidia was measured by adding $10 \mu \mathrm{L}$ of conidial solution to hemocytometer (Improved Neubauer, Germany), and then the total numbers of conidia in zones $A, B, C, D$, and E were counted under the mi- 
croscope [21], followed by the calculation of the fungi concentration at $1 \times 10^{9}$ conidia $/ \mathrm{mL}$ as used for UV testing.

\subsection{Sterilization and Disinfection Procedure}

Sterilization and disinfection procedures were applied to eliminate or kill all forms of microbial agents on the surface of the workplace. All equipment was sterilized prior to use in the experiments. Erlenmeyer flasks, glass beakers, glass tubes, micro pipettes, and pipette tips were sterilized in an autoclave (HIRAYAMA, HG-80, and Japan). Moreover, the workplace was sterilized by alcohol ( $96 \%$ ) before and after the experiments to avoid contamination.

\subsection{Evaluation of the Persistence of Fungi Isolates under UV-B Exposures}

Laboratory screening of the most virulent isolates was carried out under ultraviolet $B$ (UV-B) irradiation (280-320 nm wavelength) [6]. Fungi isolates were tested under different UV exposure times (15, 30, 60, 120, 180, 240, and $300 \mathrm{~min}$ ), and a control $0 \mathrm{~min}$ (no irradiation) was included in the study for comparison. Two UV-B lamps (15 watts, $302 \mathrm{~nm}$ Fotodyne Inc., New Berlin, Wisconsin, Germany) were used in this study. The lamp tubes were placed horizontally above the fungi samples in the irradiation chamber $(60 \times 80 \mathrm{~cm}$, ADECO, Riyadh, Saudi Arabia). The samples were kept $20 \mathrm{~cm}$ away from the UV-B irradiation light.

\subsection{Colony-Forming Unit}

The colony-forming unit (CFU) was evaluated for each isolate included in the study. The final concentration was $1 \times 10^{9}$ conidia/mL and the fungi suspension was mixed with Tween 80 surfactant $(0.001 \%)$. Afterwards $1 \mathrm{~mL}$ of the solution was poured into small plastic cups (d: $5 \mathrm{~cm} ; \mathrm{h}: 3 \mathrm{~cm})$ using a micropipette $(1000 \mathrm{~mL})$ to give a thin layer of CFU. The samples were exposed directly to the UV-B light [6]. Each fungus suspension was adjusted to $1 \mathrm{~mL}$ (the original volume) after exposure to UV irradiation with distilled water. The suspension was then dispersed on the PDA medium layer in Petri dishes. After the UV exposure procedure, plates were covered with aluminum foil and kept in an incubator (Orbital Incubator, Stuart SI500) under $25 \pm 1{ }^{\circ} \mathrm{C}$ temperature and $85 \pm 5 \%$ relative humidity in dark conditions [6]. The dishes were observed daily over 3 days until the CFU in the control were fully grown on PDA media. CFU was used to calculate the survival rate after UV irradiation in most of the UV studies in fungus tolerance [9-11]. The $\mathrm{CFU}$ were counted by observing the relative percentage of the culture which was measured using an equation given as below.

$$
\text { Relative culturability }(\%)=(\mathrm{Mt} / \mathrm{Mc}) \times 100
$$

Here $\mathrm{Mt}$ is the mean number of $\mathrm{CFU}$ of the three replicates at exposure time $\mathrm{t}$, and $\mathrm{Mc}$ is the mean number of CFU for all control dishes [6].

\subsection{Statistical Analysis}

The experiment was laid out according to completely randomized design (CRD). Numbers of CFU were calculated from survival percentage of fungi. Relative culturability was estimated for all isolates grown on PDA media. Ultraviolet irradiations were considered as main effects and non-germinated individual conidia as a response variable. The results were analyzed by analysis of variance (ANOVA). The means were compared using least significant difference (LSD) test with threshold of $p<0.05$ [22].

\section{Results}

\subsection{Evaluation of the Persistence of Fungi Isolates under UV-B Exposures}

The results revealed that all tested isolates were affected by UV-B irradiation with varying CFU survival rates (Table 2). The number of CFU significantly differed after 
exposure to UV-B for different times for the tested isolates, i.e., "BbSA-1" (F: 69.8; df: 7, 16; $p<0.0001)$, "BbSA-2" (F: 129.7; df: 7, 16; $p<0.0001)$, "BbSA-3" (F: 44; df: 7, 16; $p<0.0001$ ), "BbIDN-1" (F: 346.1; df: 7, 16; $p<0.0001)$, “MaSA-1" (F: 66.8; df: 7, 16; $p<0.0001)$, "MaIDN1" (F: 31.4; df: 7, 16; $p<0.0001$ ), and "MaIDN-2" (F: 63.9; df: 7, 16; $p<0.0001$ ). The mean number of CFU after exposure to UV-B irradiation for 300 min was 29.2 for "MaSA-1", 25.7 for "MaIDN-2", 11.6 for "BbSA-1", 11 for "MaIDN-1", 10 for "BbSA-2", 0 for "BbSA-3", and 0 for "BbIDN-1". The isolates "BbSA-3" and "BbIDN-1" were highly sensitive to all UV-B exposure times. The number of CFU in each isolate decreased with increasing UV-B exposure time.

Table 2. The effect of different UV-B irradiation exposure times on fungi isolate persistency based on the number of colony-forming units (CFU).

\begin{tabular}{|c|c|c|c|c|c|c|c|c|c|}
\hline \multirow{3}{*}{$\begin{array}{l}\text { Isolate } \\
\text { Name }\end{array}$} & \multirow{3}{*}{$\begin{array}{l}\text { Isolate } \\
\text { Code }\end{array}$} & \multicolumn{8}{|c|}{ Colony-Forming Unit (CFU)/Ml of Fungus Isolate } \\
\hline & & \multicolumn{8}{|c|}{ UV-B Exposure Times } \\
\hline & & $\begin{array}{c}0 \\
\text { Min }\end{array}$ & $\begin{array}{c}15 \\
\text { Min }\end{array}$ & $\begin{array}{c}30 \\
\text { Min }\end{array}$ & $\begin{array}{c}60 \\
\text { Min }\end{array}$ & $\begin{array}{l}120 \\
\text { Min }\end{array}$ & $180 \mathrm{Min}$ & 240 Min & $300 \mathrm{Min}$ \\
\hline \multirow{4}{*}{ B. bassiana } & BbSA-1 & $433 \pm 30^{a}$ & $355 \pm 32^{b}$ & $203 \pm 26^{c}$ & $143 \pm 7^{\mathrm{d}}$ & $127 \pm 10^{d}$ & $33 \pm 5^{e}$ & $18 \pm 4^{\mathrm{e}}$ & $11.6 \pm 3^{\mathrm{e}}$ \\
\hline & BbSA-2 & $311 \pm 5^{a}$ & $247 \pm 16^{b}$ & $212 \pm 17^{c}$ & $105 \pm 14^{\mathrm{d}}$ & $62 \pm 3^{e}$ & $26 \pm 1^{\mathrm{f}}$ & $20 \pm 3^{f}$ & $10 \pm 1^{\mathrm{f}}$ \\
\hline & BbSA-3 & $368 \pm 30^{a}$ & $323 \pm 45^{a b}$ & $275 \pm 23^{b c}$ & $225 \pm 28^{c}$ & $31 \pm 4^{\mathrm{d}}$ & $19 \pm 3^{d}$ & $20 \pm 2^{\mathrm{d}}$ & $0 \pm 0^{\mathrm{d}}$ \\
\hline & BbIDN-1 & $340 \pm 13^{a}$ & $95 \pm 10^{b}$ & $48 \pm 3^{c}$ & $43 \pm 7^{c d}$ & $25 \pm 2^{\mathrm{de}}$ & $15 \pm 2^{\text {ef }}$ & $13 \pm 0.1^{\text {ef }}$ & $0 \pm 0^{\mathrm{f}}$ \\
\hline \multirow{3}{*}{ M. anisopliae } & MaIDN-1 & $420 \pm 30^{a}$ & $305 \pm 20^{b}$ & $259 \pm 10^{b c}$ & $197 \pm 36^{\mathrm{cd}}$ & $146 \pm 2^{\mathrm{de}}$ & $104 \pm 25^{\text {ef }}$ & $69 \pm 9 \mathrm{fg}$ & $11 \pm 0.5^{\mathrm{g}}$ \\
\hline & MaIDN-2 & $453 \pm 29^{a}$ & $355 \pm 31^{b}$ & $328 \pm 17^{b}$ & $213 \pm 8^{c}$ & $162 \pm 26^{c}$ & $89 \pm 7^{\mathrm{d}}$ & $39 \pm 8$ de & $25 \pm 3^{\mathrm{e}}$ \\
\hline & MaSA-1 & $439 \pm 24^{a}$ & $293 \pm 9^{b}$ & $250 \pm 10^{b c}$ & $238 \pm 13^{c}$ & $207 \pm 14^{\mathrm{cd}}$ & $171 \pm 23^{\mathrm{d}}$ & $47 \pm 6^{\mathrm{e}}$ & $29 \pm 4^{\mathrm{e}}$ \\
\hline
\end{tabular}

The mean number of colony forming units (CFU) \pm SE is shown. Within each row, means followed by the same letters do not differ significantly (LSD test at $p<0.05$ ).

The surviving CFU after UV-B irradiation can germinate on PDA medium in the Petri dishes. The number of CFU of all isolates decreased after exposure to UV-B irradiation for 15-300 min compared to control treatment (no exposure to UV-B) (Figure 1).

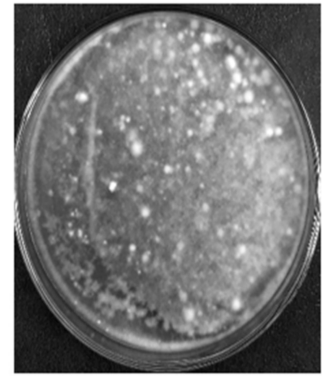

Non-irradiated CFU

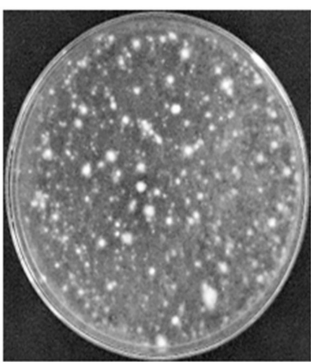

CFU after 120 minutes

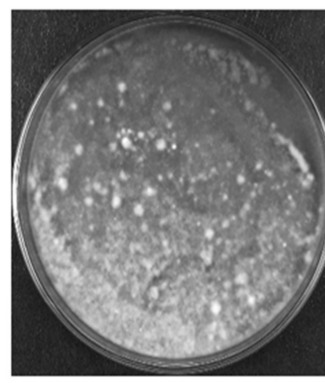

CFU after 15 minutes

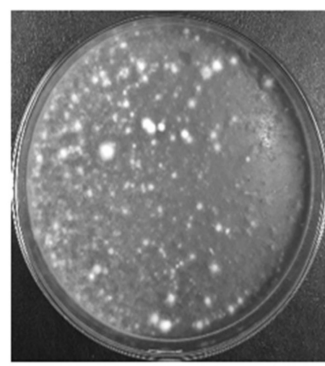

CFU after 180 minutes

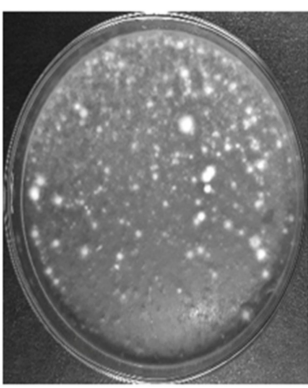

CFU after 30 minutes

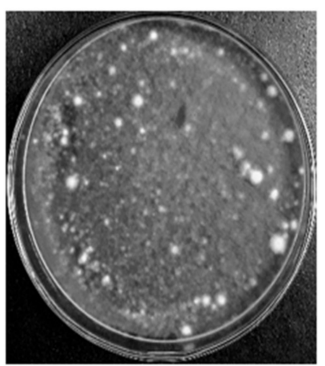

CFU after 240 minutes

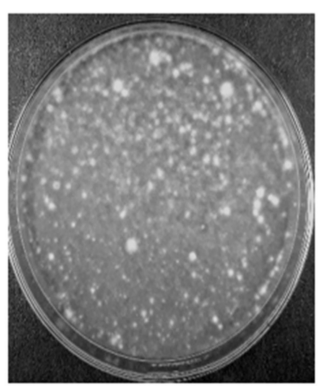

CFU after 60 minutes

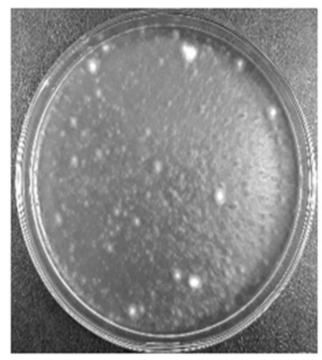

CFU after 300 minutes

Figure 1. A comparison for CFU of the fungus isolate "MaSA-1" growth on PDA medium after UV-B irradiation at different exposure time. 


\subsection{Relative Culturability of Fungi Isolates after Ultraviolet B (UV-B) Irradiation}

The effect of UV on the culturability percentage of Beauveria bassiana isolate "BbSA-1" is shown in Figure 2. Based on the mean number of CFU after growing on PDA medium, the culturability \% of $B$. bassiana isolate "BbSA-1" decreased significantly for all exposure durations (F: 36.7; df: 7, 16; $p<0.0001$ ). The culturability percentage decreased as exposure time increased, indicating that UV-B was influencing it in a direct proportionate manner.

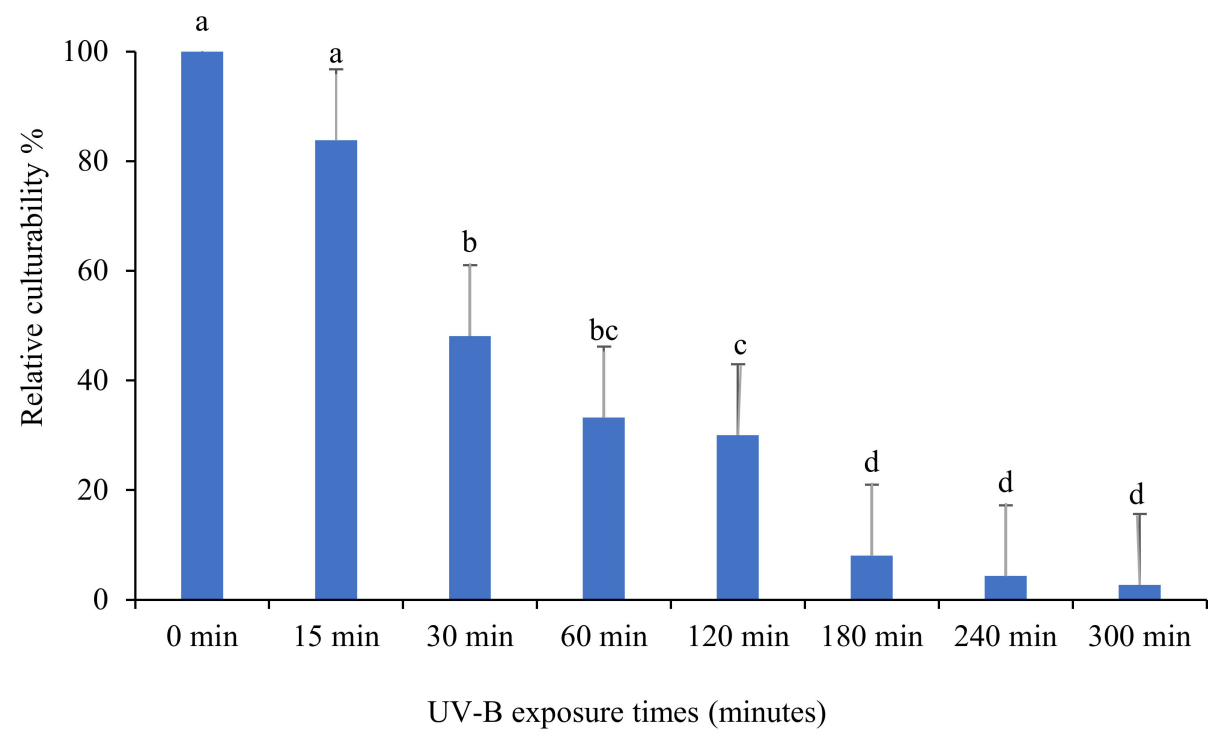

Figure 2. The impact of different UV-B exposure times on relative culturability percentage of Beauveria bassiana isolate "BbSA-1". The mean number of relative culturability percentage \pm SE is shown. Different letters on the same patterned bars indicate significant differences (LSD test, $p<0.05)$.

The impact of ultraviolet light on the culturability of the B. bassiana isolate "BbSA-2" is shown in Figure 3. The percentage of culturability was significantly different in response to different exposure times for "BbSA-2" (F: 129.4; df: 7, 16; $p<0.0001$ ). After 300 min of UV-B exposure, the CFU of this isolate has decreased after growing on PDA medium, but it still persists.

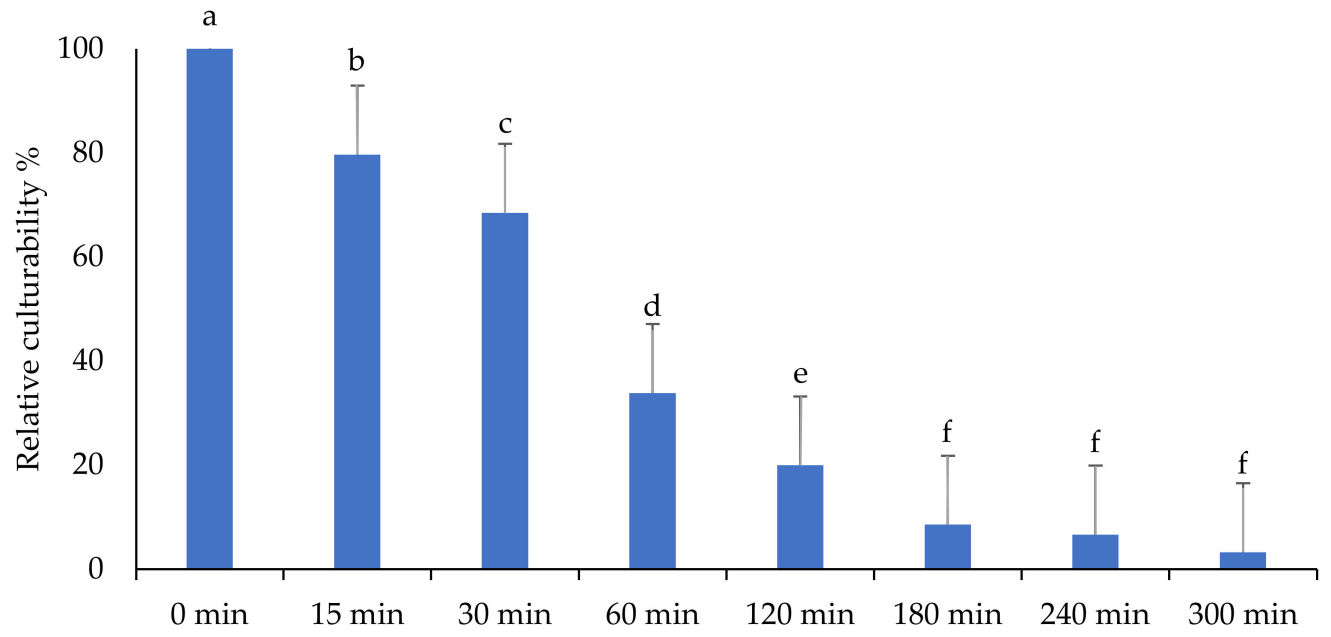

UV-B exposure time (minutes)

Figure 3. The impact of different UV-B exposure times on relative culturability percentage of Beauveria bassiana isolate "BbSA-2". The mean number of relative culturability percentage \pm SE is shown. Different letters on the same patterned bars indicate significant differences (LSD test, $p<0.05$ ). 
After UV-B irradiation, the culturability percentage of B. bassiana isolate "BbSA-3" is presented in Figure 4. Similar to other isolates, there was a significant decrease in the culturability percentage response of "BbSA-3" isolate at different exposure intervals (F: 62.9; df: 7,$16 ; p<0.0001)$. The percentage of culturability decreased as exposure time increased, but CFU decreased after growing on PDA medium and did not persist after 300 min of UV-B exposure.

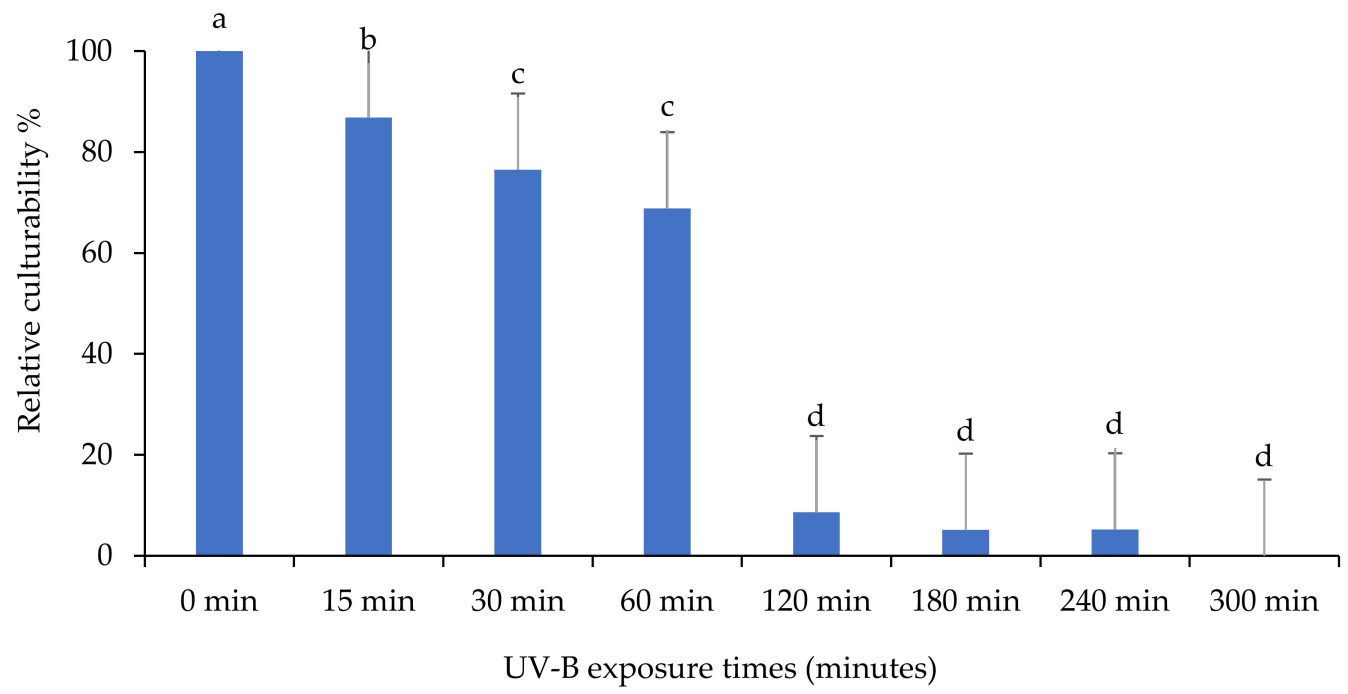

Figure 4. The impact of different UV-B exposure times on relative culturability percentage of Beauveria bassiana isolate "BbSA-3". The mean number of relative culturability percentage $\pm \mathrm{SE}$ is shown. Different letters on the same patterned bars indicate significant differences (LSD test, $p<0.05$ ).

The effect of UV light on the culturability of the B. bassiana isolate "BbIDN-1" is shown in Figure 5. For "BbIDN-1", the percentage of culturability showed significant differences in response at different exposure times (F: 671.6; df: 7, 16; $p<0.0001$ ). With increasing exposure time, the percentage of culturability decreased, but CFU did not persist after 300 min of UV-B exposure. In comparison to other B. bassiana isolates, this isolate is highly sensitive to UV-B irradiation.

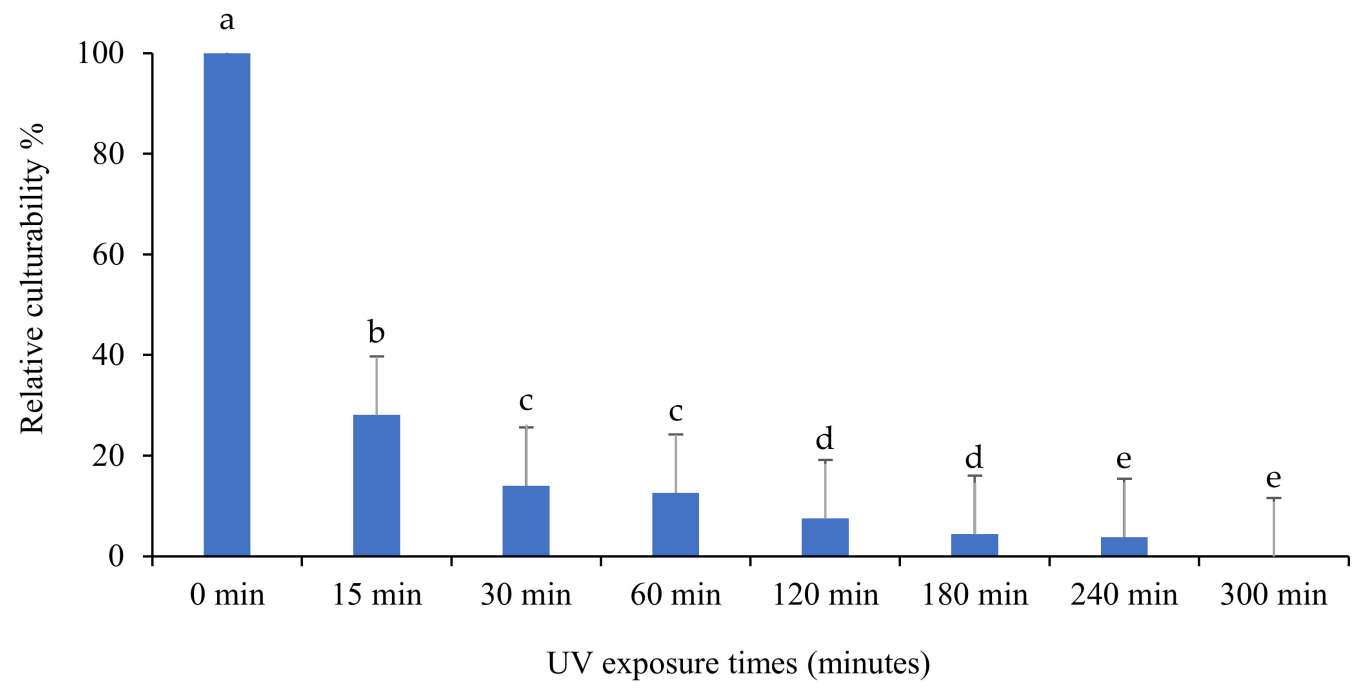

Figure 5. The impact of different UV-B exposure times on relative culturability percentage of Beauveria bassiana isolate "BbIDN-1". The mean number of relative culturability percentage \pm SE is shown. Different letters on the same patterned bars indicate significant differences (LSD test, $p<0.05)$. 
The culturability percentage of Metarhizium anisopliae isolate "MaIDN-1" is presented in Figure 6. A significant difference in the percentage of culturability in response to different exposure times was observed for "MaIDN-1" (F: 38.9; df: 7, 16; $p<0.0001$ ). The number of CFU was decreased after growing on PDA medium, but CFU still persisted after $300 \mathrm{~min}$ UV-B exposure.

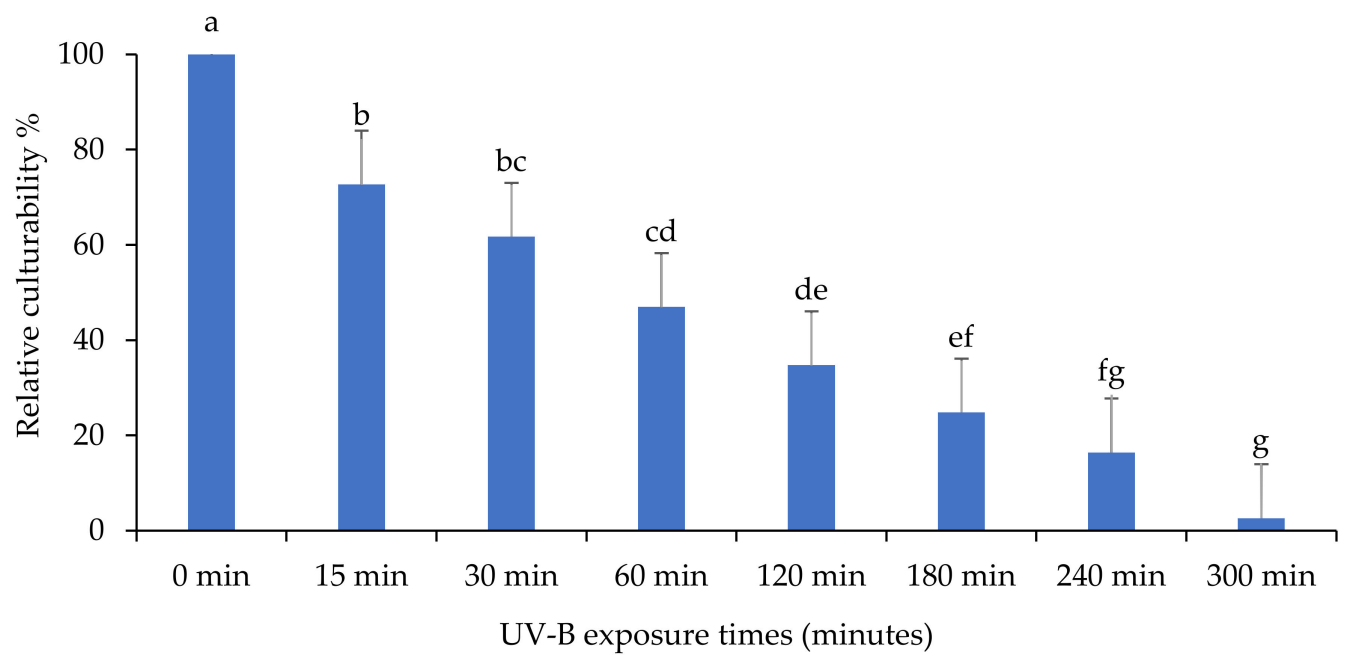

Figure 6. The impact of different UV-B exposure times on relative culturability percentage of Metarhizium anisopliae isolate "MaIDN-1". The mean number of relative culturability percentage \pm SE is shown. Different letters on the same patterned bars indicate significant differences (LSD test, $p<0.05)$.

The effect of UV on the culturability percentage of M. anisopliae isolate "MaIDN-2" is presented in Figure 7. For "MaIDN-2", there was a significant difference in the percentage of culturability in response to different exposure times (F: 51.8; df: 7, 16; $p<0.0001$ ). Similarly, the number of CFU was decreased, however, CFU still remained after $300 \mathrm{~min}$ of UV-B exposure.

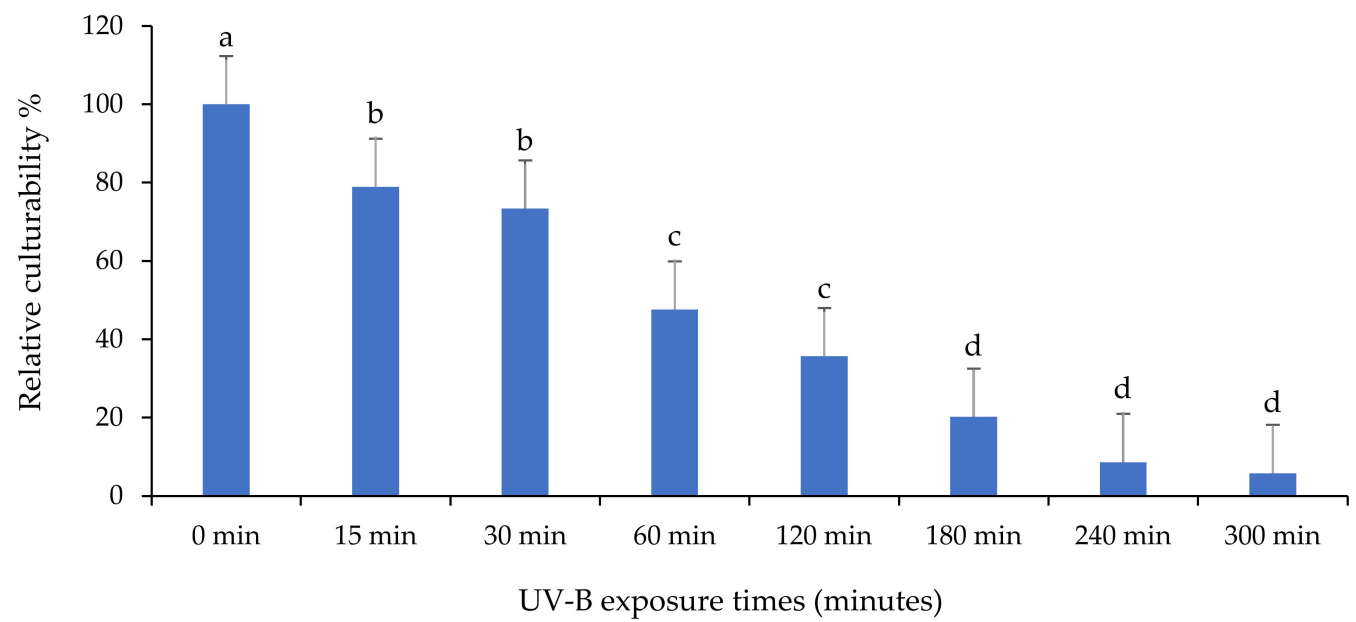

Figure 7. The impact of different UV-B exposure times on relative culturability percentage of Metarhizium anisopliae isolate "MaIDN-2". The mean number of relative culturability percentage $\pm \mathrm{SE}$ is shown. Different letters on the same patterned bars indicate significant differences (LSD test, $p<0.05)$.

The impact of ultraviolet light on the culturability of the M. anisopliae isolate "MaSA$1^{\prime \prime}$ is shown in Figure 8. The culturability percentage of M. anisopliae isolate decreased significantly for all exposure durations based on the mean number of CFU after growing 
on PDA medium "MaSA-1" (F: 46.1; df: 7, 16; $p<0.0001$ ). Similar to other isolates, the number of CFU decreased, but CFU remained after $300 \mathrm{~min}$ of UV-B exposure, indicating that this isolate is persistent.

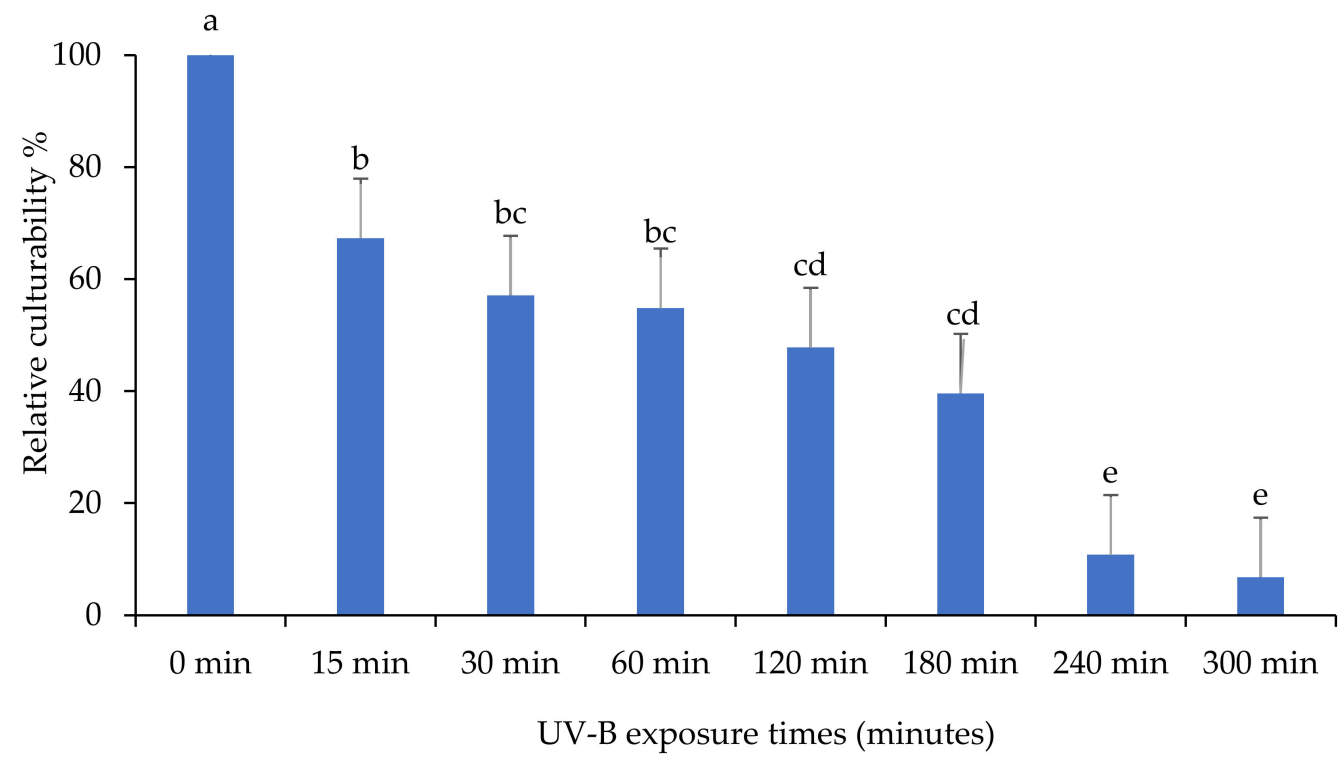

Figure 8. The impact of different UV-B exposure times on relative culturability percentage of Metarhizium anisopliae isolate "MaSA-1". The mean number of relative culturability percentage $\pm \mathrm{SE}$ is shown. Different letters on the same patterned bars indicate significant differences (LSD test, $p<0.05)$.

\section{Discussion}

The current study indicated that the number of CFU of each isolate decreased after exposure to UV-B irradiation for different times. UV-B rays had a negative effect on the germination rate of conidia of each isolate included in the study. The result confirmed that UV-B and UV-C are the most destructive rays for fungi isolates [5]. It has been reported that UV-B irradiation affects all fungi isolates and reduces their CFU number $[5,6,23]$. Reactive oxidation species (ROS), such as single oxygen and peroxidase, are generated after exposure of microorganisms to UV light, which have a negative effect on their DNA [3]. Moreover, biological systems of microorganisms absorb photochemicals when exposed to UV light [24]. The UV light (UV-B) caused the death of M. anisopliae conidia and inhibited their germination [25]. In this study, UV-B irradiation affected the conidia germination of fungal isolates included in the study. However, conidial dormancy has been regarded as the key characteristic for most of UV-tolerant fungi isolates [26]. In the present study, the viability of each fungus isolate was determined by the germination of conidia after UV irradiation.

In our study conidia germinated 2-3 days after incubation. This can be supported by another study reporting that CFU of fungi typically remain viable within 2-5 days after exposure to UV irradiation and it greatly depends on the cell type exposed to the irradiation [5]. The CFU of M. anisopliae was observed when irradiated to UV-C for $50 \mathrm{~s}$ and CFU decreased to $1.11 \times 10^{8}$ conidia/mL, while the CFU under non-irradiated conditions were $11.13 \times 10^{8}$ conidia/mL [27]. Our study determined which fungi isolates can survive after exposure to UV-B irradiation. The survival rate based on the number of CFU of fungi isolates determines conidia germination [6,27-29].

Ultraviolet irradiation changed Cyclobutane pyrimidine dimer (CPD) formation in DNA resulting in decreased conidia viability of B. bassiana [5]. Although UV irradiationinduced DNA damage chemically alters DNA components, DNA can be repaired by removing site lesions [30]. Physical protection (such as pigmented fungi) could increase tolerance and survival of $M$. anisopliae against UV [31]. However, UV-B exposure decreased 
viability and pathogenicity of M. anisopliae [20], and delayed germination [14,28]. In the present study fungi isolates "BbSA-3" and "BbIDN-1" lost their activity (germination) faster than the isolates "MaSA-1", "BbSA-1", "MaIDN-1", "MaIDN-2", and "BbSA-2". In addition, CFU values of fungi isolates decreased after exposure to UV-B irradiation. The highest number of CFU after 300 min UV-B exposure were 29.2 recorded for the isolate "MaSA-1". This might be linked to the high concentration of fungi isolates that protected it against UV-B irradiation. Similarly, the high concentration could protect B. bassiana from UV irradiation [32].

Several studies have investigated the effect of UV irradiation on germination of different fungi isolates. The germination rate of $M$. anisopliae decreased by $50 \%$ after $1 \mathrm{~h}$ exposure to UV-B irradiation, while 3\% of conidia remained viable after $12 \mathrm{~h}$ exposure [33]. Similarly, reduction in conidia germination after 5 min of exposure to UV-B was $94 \%$ to $52 \%$ and $96 \%$ to $54 \%$ for B. bassiana and $M$. anisopliae, respectively [34]. B. bassiana and $M$. anisopliae conidia were significantly affected when they were exposed to UV-B for 1-2 h [35]. It has been reported that dried entomopathogenic fungi such as $M$. anisopliae was the most tolerant to UV-B irradiation compared to B. bassiana when exposed to UV irradiation for $4 \mathrm{~h}$ [36].

However, M. acridum isolate proved tolerant to UV-B after exposure to white light (visible light) for $2 \mathrm{~h}$ based on germination rate [37]. M. anisopliae and P. fumoroseus, (Eurotiales: Trichocomaceae) exhibited varied tolerance to UV-B irradiation [38]. Several local isolates of B. bassiana and $M$. anisopliae have been tested under UV-B irradiation and $B$. bassiana proved more tolerant than $M$. anisopliae. Nonetheless, $M$. anisopliae tolerated high temperature $\left(37^{\circ} \mathrm{C}\right)$ [39]. A review study showed varied susceptibility of fungi isolates to UV irradiation [11]. The survival rate of M. anisopliae conidia was $0 \%$ to $1 \%$ after $8 \mathrm{~h}$ exposure to UV-B, while M. flavoviridae, (Hypocreales: Clavicipitaceae) had 0\% to $11 \%$ survival, indicating that $M$. flavoviridae was more tolerant to simulated sunlight [40]. The sensitivity of several UV-B isolates varies depending on culture age. For example, $M$. anisopliae and B. bassiana proved more tolerant to UV-B irradiation when the culture was air dried for 14 days compared to 7 days [13]. We conclude that "MaSA-1" isolate can be selected for further field testing based on its high survival rate under UV exposure in the laboratory.

In an additional case study, fungi survival after UV exposure resulted in increased germination and pathogenicity [28]. Isolates of $M$. anisopliae responded differently to UV-B irradiation; however, surviving conidia were the most virulent to grasshoppers Schistocerca gregaria, (Orthoptera: Acrididae) after being exposed to UV for $8 \mathrm{~h}$, and their germination rates ranged from $79.4 \%$ to $91.6 \%$ [41]. In contrast, UV irradiation reduced the vegetative growth and conidial sporulation of $B$. bassiana strains after successive passages of coleopteran host, i.e., lesser mealworm Alphitobius diaperinus (Panzer) (Coleoptera: Tenebrionidae) [42]. The germination and infection of fungal isolates B. bassiana and M. anisopliae were evaluated on red palm weevil Rhynchophorus ferrugineus Olivier (Coleoptera: Dryophthoridae) in laboratory condition, and exhibited more efficient control, but the germination of both fungal isolates was sharply reduced when exposed to sunlight condition at different seasons [12].

Moreover, the use of several microbial agents to control red palm weevil have been well documented [43]. For example, B. bassiana and M. anisopliae have been reported to be a key determinant in suppressing $R$. ferrugineus populations in the field [44]. This may explain why entomopathogenic fungi are the best microbial agents for controlling this pest in the field. However, the pathogenicity of various fungi isolates has recently been tested in the laboratory against red palm weevil stages [17]. When compared to other microbial agents, such as the nematode genus Steinernema and Heterorhabditis, it showed that different nematode isolates had different mortality responses, especially in the red palm weevil larvae and adult stages [45]. Another study showed that using a combination of fungus, M. anisopliae, and nematode, Heterorhabditis sp. (Rhabditida: Heterorhabditidae) to control 
coconut beetle larvae Oryctes rhinoceros, (Coleoptera: Scarabaeidae) had a positive result, with high mortality [46].

However, in this study, the selection of fungi isolates is quite important and could be supported in order to achieve long-term performance when applied in the field, as we know that fungi isolates exhibit varying response to UV irradiation based on the association between geographical origin [47], conidial pigmentation [31,48], and host insects [39].

\section{Conclusions}

The complete inactivation of conidia belonging to the isolates "BbSA-3" and "BbIDN-1" was recorded at a concentration of $1 \times 10^{9}$ conidia/mL, while other isolates, i.e., "MaSA-1", "BbSA-1", "MaIDN-1", "MaIDN-2", and "BbSA-2", persisted after 300 min exposure to UV-B irradiation. Our findings reveal that the surviving fungi isolates after UV exposures may possess increased germination performance. The surviving isolates should be tested under field conditions for making general recommendations and to achieve the overall goal of this work, to obtain sustainable control of the red palm weevil, which has become a major invasive pest in many areas outside its native habitat. Furthermore, the survival fungus should be tested with various delivery systems and in various seasons to determine its efficacy in the field.

Author Contributions: Conceptualization, K.G.R. and A.S.A.; data curation, K.D.S., M.H. and W.H.A.-Q.; methodology, K.D.S., M.H. and A.F.M.; software, K.D.S. and W.H.A.-Q.; writing-original draft preparation, K.D.S.; writing-review and editing, M.H., K.G.R., A.F.M., W.H.A.-Q. and A.S.A. All authors have read and agreed to the published version of the manuscript.

Funding: This work was supported by the Researchers Supporting Project number (RSP-2021/107), King Saud University, Riyadh, Saudi Arabia.

Institutional Review Board Statement: Not applicable.

Informed Consent Statement: Not applicable.

Data Availability Statement: All relevant data are within the paper.

Acknowledgments: The authors would like to thank the Researchers Supporting Project, King Saud University, Riyadh, Saudi Arabia for financial support of the present work through project number RSP-2021/107. Moreover, the authors extend their thanks to Yasser and Elkomy in Microbiology laboratory unit, Plant Protection Department, College of Agricultures, King Saud University for their guidance during the work.

Conflicts of Interest: The authors declare no conflict of interest.

\section{References}

1. Vidyasagar, P.S.P.V.; Al Saihati, A.A.; Al Mohanna, O.E.; Subbei, A.I.; Abdul Mohsin, A.M. Management of red palm weevil Rhynchophorus ferrugineus Oliv., A serious pest of date palm in Al Qatif, Kingdom of Saudi Arabia. J. Plant Crops. 2000, 28 , 35-43.

2. Cutler, T.D.; Zimmerman, J.J. Ultraviolet irradiation and the mechanisms underlying its inactivation of infectious agents. Anim. Health Res. Rev. 2011, 12, 15-23. [CrossRef] [PubMed]

3. Bandyopadhyay, U.; Das, D.; Banerjee, R.K. Reactive oxygen species: Oxidative damage and pathogenesis. Review Article. Curr. Sci. 1999, 77, 658-666.

4. Schuch, A.P.; Morenob, N.C.; Schuchc, N.J.; Menckb, C.F.M.; Garciad, C.C.M. Sunlight damage to cellular DNA: Focus on oxidatively generated lesions. Free Radic. Biol. Med. 2017, 107, 110-124. [CrossRef]

5. Chelico, L.; Haughian, J.L.; Woytowich, A.E.; Khachatourians, G.G. Quantification of Ultraviolet-C irradiation induced cyclobutane pyrimidine dimers and their removal in Beauveria bassiana conidiophores DNA. Mycologia 2005, 97, 621-627. [CrossRef]

6. Braga, G.U.L.; Rangel, D.E.N.; Flint, S.D.; Miller, C.D.; Anderson, A.J.; Roberts, D.W. Damage and recovery from UV-B exposure in conidia of the enthomopathogens Verticilium lecanii and Aphanocladium album. Mycologia 2002, 94, 912-920. [CrossRef]

7. Huarte-Bonnet, C.; Pereira-Junior, R.A.; Paixao, F.R.A.; Braga, G.U.L.; Roberts, D.W.; Luz, C.; Pedrini, N.; Fernandes, E.K.K. Metarhizium robertsii and M. acridum conidia produced on riboflavin-supplemented medium have increased UV-A tolerance and upregulated photoprotection and photoreactivation genes. BioControl 2020, 65, 211-222. [CrossRef]

8. Kaiser, D.; Bacher, S.; Mène-Saffrané, L.; Grabenwegera, G. Efficiency of natural substances to protect Beauveria bassiana conidia from UV radiation. Pest Manag. Sci. 2018, 75, 556-563. [CrossRef] 
9. Herlinda, S.; Rizkie, L.; Suwandi; Susilawati; Lakitan, B.; Verawaty, M.; Hasbi. Effects of High Temperature and Ultraviolet-C Irradiance on Conidial Viability and Density of Beauveria Bassiana and Metarhizium Anisopliae Isolated from Soils of Lowland Ecosystems in Indonesia. Eurasian J. Anal Chem. 2018, 13, 209-216.

10. Couceiro, J.D.C.; Fatoretto, M.B.; Demétrio, C.G.B.; Meyling, N.V.; Delalibera, I.J. UV-B Radiation Tolerance and TemperatureDependent Activity within the Entomopathogenic Fungal Genus Metarhizium in Brazil. Front. Fungal Biol. 2021, 2, 6. [CrossRef]

11. Fernandes, É.K.K.; Rangel, D.E.N.; Braga, G.U.; Roberts, D.W. Tolerance of fungi to ultraviolet radiation: A review on screening of strains and their formulation. Curr. Genet. 2015, 61, 427-440. [CrossRef]

12. Francardi, V.; Benvenuti, C.; Paolobarzanti, G.; Roversi, P.F. Auto-contamination trap with fungi: A possible strategy in the control of Rhynchophorus ferrugineus (Oliver) (Coleoptera: Curculionidae). Redia 2013, 96, 57-67.

13. Le Grand, M.; Cliquet, S. Impact of culture age on conidial germination, desiccation and UV tolerance of entomopathogenic fungi. Biocontrol Sci. Technol. 2013, 23, 847-859. [CrossRef]

14. Cagáň, L'.; Švercel, M. The influence of ultraviolet light on pathogenicity of entomopathogenic fungi Beauveria bassiana (balsamo) vuillemin to the european corn borer, Ostrinia nubilalis hbn. (Lepidoptera: Crambidae). J. Cent. Eur. Agric. 2021, 2, 228-234. [CrossRef]

15. Tobar, S.P.; Vélez-Arango, P.E.; Montoya-Restrepo, E.C. Evaluación en campo de un aislamiento de Beauveria bassiana seleccionado por resistencia a la luz ultravioleta. Cenicafé 1999, 50, 195-204.

16. Humber, R.A. Fungi: Identification Manual of Techniques in Insect Pathology; Academic Press: New York, NY, USA, $2012 ;$ pp. 151-187.

17. Sutanto, K.D.; Husain, M.; Rasool, K.G.; Al-Qahtani, W.H.; Aldawood, A.S. Pathogenicity of local and exotic entomopathogenic fungi isolates against different life stages of red palm weevil (Rhynchophorus ferrugineus). PLoS ONE 2021, 16, e0255029. [CrossRef]

18. Sahayaraj, K.; Namasivayam, S.K.R. Mass production of fungi using agricultural products and by products. Afr. J. Biotechnol. 2008, 7, 1907-1910. [CrossRef]

19. Gutierrez-Coarite, R.; Javier, M.; Lisa, K.; Wade, P.H.; Lionel, S.; Mark, G.W.; Stacey, C. Entomopathogenic Fungi as Mortality Factors of Macadamia Felted Coccid, Eriococcus ironsidei (Hemiptera: Eriococcidae) in Hawaii. Proc. Hawaii. Entomol. Soc. 2018, $50,9-16$.

20. El Husseini, M.M. Efficacy of the fungus Beauveria bassiana (Balsamo) Vuillemin on the red palm weevil Rhynchophorus ferrugineus Olivier (Coleoptera: Curculionidae) larvae and adults under laboratory conditions. Egypt J. Biol. Pest Control 2019, $29,58$. [CrossRef]

21. Oliveira, D.G.P.; Pauli, G.; Mascarin, G.M.; Delalibera, I. A protocol for determination of conidial viability of the fungal entomopathogens Beauveria bassiana and Metarhizium anisopliae from commercial products. J. Microbiol. Methods 2015, 119, 44-52. [CrossRef]

22. SAS. SAS/STAT ${ }^{\circledR}$ 9.1. Users Guide; SAS Institute: Cary, NC, USA, 2004; pp. 1-5136.

23. Braga, G.U.L.; Flint, S.D.; Messias, C.L.; Anderson, A.J.; Roberts, D.W. Effects of UVB Irradiance on Conidia and Germinants of the Entomopathogenic Hyphomycete Metarhizium anisopliae: A Study of Reciprocity and Recovery. Photochem. Photobiol. 2001, 73, 140-146. [CrossRef]

24. Diffey, B.L. Solar ultraviolet radiation effects on biological system. Phys. Med. Biol. 1991, 36, 299. [CrossRef]

25. Alves, R.T.; Bateman, R.P.; Prior, C.; Leather, S.R. Effects of simulated solar radiation on conidial germination of Metarhizium anisopliae in different formulations. Crop Prot. 1998, 17, 675-679. [CrossRef]

26. Braga, G.U.L.; Rangel, D.E.N.; Fernandes, E.K.K.; Roberts, D.W. Molecular and physiological effects of environmental UV radiation on fungal conidia. Curr. Genet. 2015, 61, 405-425. [CrossRef]

27. Ottati-De-Lima, E.L.; Filho, A.B.; Almeida, J.E.M.D.; Gassen, M.H.; Wenzel, I.M.; Almeida, A.M.B.D.; Zapellini, L.O. Liquid production of entomopathogenic fungi and ultraviolet radiation and temperature effects on produced propagules. Arq. Inst. Biol. 2014, 81, 342-350. [CrossRef]

28. Morley-Davies, J.; Moore, D.; Prior, C. Screening of Metarhizium and Beauveria spp. conidia with exposure to simulated sunlight and a range of temperatures. Mycol. Res. 1995, 100, 31-38. [CrossRef]

29. Fang, W.; St Leger, R.J. Enhanced UV Resistance and Improved Killing of Malaria Mosquitoes by Photolyase Transgenic Entomopathogenic Fungi. PLoS ONE 2012, 7, e0043069. [CrossRef]

30. Chatterjee, N.; Walker, G.C. Mechanisms of DNA Damage, Repair, and Mutagenesis. Environ. Mol. Mutagen. 2017, 58, 235-263. [CrossRef]

31. Braga, G.U.L.; Rangel, D.E.N.; Flint, S.D.; Anderson, A.J.; Roberts, D.W. Conidial Pigmentation Is Important to Tolerance Against Solar-simulated Radiation in the Entomopathogenic fungi Metarhizium anisopliae. Photochem. Photobiol. 2006, 82, 418-422. [CrossRef]

32. Hu, W.; Hou, R.F.; Talekar, N.S. Pathogenicity of Beauveria bassiana to Riptortus linearis (Hemiptera: Coreidae), a pest of soybean. Appl. Entomol. Zool. 1996, 31, 187-194. [CrossRef]

33. Loong, C.Y.; Sajap, A.S.; Noor, H.M.; Omar, D.; Abood, F. Effects of UV-B and Solar Radiation on the Efficacy of Isaria fumosorosea and Metarhizium anisopliae (Deuteromycetes: Hyphomycetes) for Controlling Bagworm, Pteroma pendula (Lepidoptera: Psychidae). J. Entomol. 2013, 10, 53-65. [CrossRef]

34. Rodrigues, I.; Forim, M.; Silva, M.; Fernandes, J.; Filho, A. Effect of Ultraviolet Radiation on Fungi Beauveria bassiana and Metarhizium anisopliae, Pure and Encapsulated, and Bio-Insecticide Action on Diatraea saccharalis. Adv. Entomol. 2016, 4, 151-162. [CrossRef] 
35. Acheampong, M.A.; Hill, M.P.; Moore, S.D.; Coombes, C.A. UV sensitivity of Beauveria bassiana and Metarhizium anisopliae isolates under investigation as potential biological control agents in South African citrus orchards. Fungal Biol. 2020, 124, 304-310. [CrossRef] [PubMed]

36. Jones, K.A.; Burges, H.G. Introduction. In Formulation of Microbial Biopesticides, Beneficial Microorganisms, Nematodes and Seed Treatments; Burges, H.D., Ed.; Kluwer Academic: London, UK, 1998; pp. 1-4.

37. Brancini, G.T.P.; Rangel, D.E.N.; Braga, G.Ú.L. Exposure of Metarhizium acridum mycelium to light induce tolerance to UV-B radiation. Microbiol. Lett. 2016, 363, fnw036. [CrossRef] [PubMed]

38. Rangel, D.E.N.; Roberts, D.W. Inducing UV-B tolerance of Metarhizium anisopliae var. anisopliae conidia results in a tradeoff between conidial production and conidial stress tolerance. J. Anhui Agric. Univ. 2007, 34, 195-202.

39. Mustafa, U.; Kaur, G. UV-B radiation and temperature stress causes variable growth response in Metarhizium anisopliae and Beauveria bassiana isolates. Internet J. Microbiol. 2008, 7, 1-8. [CrossRef]

40. Fargues, J.; Goettel, M.S.; Smits, N.; Ouedraogo, A.; Vidal, C.; Lacey, L.L.; Lomer, C.J.; Rougier, M. Variability in susceptibility to simulated sunlight of conidia among isolates of entomopathogenic Hyphomycetes. Mycopathologia 1996, 135, 171-181. [CrossRef] [PubMed]

41. Rangel, D.E.N.; Braga, G.U.L.; Anderson, A.J.; Roberts, D.W. Variability in conidial thermotolerance of Metarhizium anisopliae isolates from different geographic origins. J. Invertbr. Pathol. 2005, 88, 116-125. [CrossRef]

42. Santoro, P.H.; Zorzetti, J.; Constanski, K.; Neves, P.M.O.J. Quality of Beauveria bassiana conidia after successive passages through Alphitobius diaperinus (Coleoptera: Tenebrionidae). Rev. Colomb. Entomol. 2015, 41, 87-94.

43. Mazza, G.; Francardi, V.; Simoni, S.; Benvenuti, C.; Cervo, R.; Faleiro, J.R.; Llacer, E.; Longo, S.; Nannelli, R.; Tarasco, E.; et al. An overview on the natural enemies of Rhynchophorus palm weevils, with focus on R. ferrugineus. Biol. Control 2014, 77, 83-92. [CrossRef]

44. Tarasco, E.; Porcelli, F.; Poliseno, M.; Quesada, M.E.; Santiago, Á.C.; Triggiani, O. Natural occurrence of entomopathogenic fungi infecting the Red Palm Weevil Rhynchophorus ferrugineus (Olivier, 1790) (Coleoptera: Curculionidae) in southern Italy. IOBC/WPRS Bull. 2008, 31, 195-197.

45. Triggiani, O.; Tarasco, E. Evaluation of the effects of autochthonous and commercial isolates of Steinernematidae and Heterorhabditidae on Rhynchophorus ferrugineus. Bull. Insectology 2011, 64, 175-180.

46. Dyah, R.I.; Priyantini, W.; Haryuni, M.S.; Yoris, A.M. Effectiveness of M. anisopliae and entomopathogenic nematodes to control Oryctes rhinoceros larvae in the rainy season. Pak. J. Biol. Sci. 2017, 20, 320-327.

47. Fernandes, É.K.K.; Rangel, D.E.N.; Moraes, A.M.L.; Bittencourt, V.R.E.P.; Roberts, D.W. Variability in tolerance to UV-B radiation among Beauveria spp. isolates. J. Invertebr. Pathol. 2007, 96, 237-243. [CrossRef]

48. Rangel, D.E.N.; Butler, M.J.; Torabinejad, J.; Anderson, A.J.; Braga, G.U.L.; Day, A.W.; Roberts, D.W. Mutants and isolates of Metarhizium anisopliae are diverse in their relationships between conidial pigmentation and stress tolerance. J. Invertbr. Pathol. 2006, 93, 170-182. [CrossRef] 